\title{
Potential role for tissue factor in the pathogenesis of hypercoagulability associated with in COVID-19
}

\author{
Mario Bautista-Vargas ${ }^{1} \cdot$ Fabio Bonilla-Abadía ${ }^{1}$ - Carlos A. Cañas ${ }^{1}$ (i)
}

Published online: 9 June 2020

(c) Springer Science+Business Media, LLC, part of Springer Nature 2020

\begin{abstract}
In December 2019, a new and highly contagious infectious disease emerged in Wuhan, China. The etiologic agent was identified as a novel coronavirus, now known as Severe Acute Syndrome Coronavirus-2 (SARS-CoV-2). Recent research has revealed that virus entry takes place upon the union of the virus $\mathrm{S}$ surface protein with the type I transmembrane metallocarboxypeptidase, angiotensin converting enzyme 2 (ACE-2) identified on epithelial cells of the host respiratory tract. Virus triggers the synthesis and release of pro-inflammatory cytokines, including IL- 6 and TNF- $\alpha$ and also promotes downregulation of ACE-2, which promotes a concomitant increase in levels of angiotensin II (AT-II). Both TNF- $\alpha$ and AT-II have been implicated in promoting overexpression of tissue factor (TF) in platelets and macrophages. Additionally, the generation of antiphospholipid antibodies associated with COVID-19 may also promote an increase in TF. TF may be a critical mediator associated with the development of thrombotic phenomena in COVID-19, and should be a target for future study.
\end{abstract}

Keywords COVID-19 $\cdot$ SARS-CoV-2 $\cdot$ Tissue factor $\cdot$ IL- $6 \cdot$ TNF- $\alpha \cdot$ Thrombosis

\section{Highlights}

- Severe forms of Covid-19 are related to thrombotic coagulopathy. Its pathogenesis involves the effect of the virus on the immune system and the downregulation of ACE2 that causes an increase in angiotensin II levels.

- Tissue factor is likely involved in this chain of events. Both proinflammatory cytokines and increased angiotensin II are known factors in its induction.

\section{Introduction}

In December 2019, a new and highly contagious infectious disease emerged in the city of Wuhan, China [1]. Some of the infected patients developed severe acute respiratory syndrome (SARS) and a systemic inflammatory response syndrome (SIRS) associated with high mortality [2]. This

Carlos A. Cañas

cacd12@hotmail.com

1 Unit of Rheumatology, Fundación Valle del Lili, Universidad Icesi, Avenida Simón Bolívar Cra.98 No.18-49, Cali,

Colombia disease rapidly disseminated worldwide and was declared to be a pandemic in March 2020 [3]. The causative agent of the new disease, Coronavirus Disease-2019 (COVID-19), was isolated and identified as a novel coronavirus, now known as Severe Acute Respiratory Syndrome Coronavirus-2 (SARS$\mathrm{CoV}-2$ ). The pathway for virus entry into target cells is analogous to that used by epidemic SARS-CoV and includes a union between the viral surface $S$ protein and its target membrane receptor, angiotensin converting enzyme 2 (ACE-2) that has been identified on cells of the respiratory epithelium [4]. Triggers numerous immunological and inflammatory responses that promote distinct clinical manifestations of COVID-19 [5]. The immune/inflammatory response may be self-limited in patients who experience mild symptoms and who have good prognosis after the infection. However, this response may be dysregulated in a smaller fraction of infected patients; these individuals progress to SARS and SIRS, both syndromes associated with a high mortality. Many of these patients develop COVID-19-associated coagulopathies, which include cerebrovascular accidents [6], acro-ischemia [7], disseminated intravascular coagulation [8] and pulmonary thromboembolism [9]. Aberrant laboratory values include prolonged prothrombin time (PT) and partial thromboplastin time (PTT), increased serum levels of 
D-dimer, low fibrinogen levels, and thrombocytopenia [10]. Anti-phospholipid antibodies have also been reported [11].

Underlying conditions and specific demographic characteristics have been associated with the likelihood of developing severe disease. Specifically, COVID-19 severity has been associated with older age and comorbidities including chronic obstructive pulmonary disease (COPD), cardiac failure, arterial hypertension, diabetes mellitus and/or smoking. Interestingly, these comorbidities have also been associated with overexpression of the ACE-2 virus receptor [12].

Factors that include ACE-2 downregulation resulting in the accumulation of angiotensin II (AT-II) due to a reduced rate of cleavage to angiotensin 1-7 (Ang 1-7) [13], and the humoral and cell-mediated hyper-immune proinflammatory responses [14] reveal a role for tissue factor (TF) in promoting a hypercoagulable state.

\section{The biological repercussions of ACE-2 overexpression, its downregulation in response to SARS-CoV-2}

Overexpression of ACE-2 has been associated with older age [15, 16], COPD [17], cardiac failure [18], arterial hypertension [19], diabetes mellitus [20] and smoking [21]. These observations parallel the known risk factors for severe disease associated with SARS-CoV-2. While this may facilitate amplification of the acute infection, ACE-2 may also be a central mediator of the host inflammatory response that has been implicated in the pathogenesis of severe COVID-19.

SARS-CoV-2 binds to and enters through cells that express ACE-2; this receptor has been identified on epithelial cells of alveoli including pneumocytes, resident macrophages and monocytes, as well as the bronchi, trachea and cardiomyocytes among others [22]. Virus binding promotes an immediate down-regulation of this cell surface receptor [23] followed by a secondary increase in levels of its endogenous substrate, AT-II. This acute increase in levels of AT-II may have direct implications for the immune, vascular endothelial and coagulation responses [24, 25].

Shen et al. [26] explored the link between ACE-2 expression and immune regulation; similar events may be associated with the pathogenesis of COVID-19. Interactions between SARS-CoV-2 genomic RNA and Toll-like receptors (TLRs) 3 and 7 will signal an acute inflammatory response involving translocation of nuclear factor kappa $\mathrm{B}$ $(\mathrm{NF}-\mathrm{KB})$ and the interferon regulatory factors (IRFs) and ultimately resulting in the synthesis and release of proinflammatory cytokines including IL-1, IL- 6 and TNF- $\alpha$ [27]. This response promotes local influx of neutrophils and monocytes/macrophages to the alveoli and activation of the adaptive immune response. Lymphopenia associated with a dysregulation of the Th1/Th2 balance has also been identified in patients with severe SARS-CoV-2 infection. Overall, these responses contribute to the incipient cytokine storm that may be associated with macrophage activation syndrome [28, 29].

Accumulation of AT-II secondary to ACE2 downregulation may promote clot formation via interactions with endothelial cells and platelets [30]; TF may be involved in this process [31]. These findings may also be associated with additional prothrombotic events that have been identified in patients diagnosed with COVID-19, including increases in serum IL-6 which has characterized activities with respect to coagulation factors [32] and platelets [33]. T lymphocytes [34] as well as the cytokines IL-6, and TNF- $\alpha$ may have direct roles in promoting microvascular damage associated with AT-II [35, 36].

\section{TF overexpression in response to ACE-2 downregulation and its association with thrombosis}

$\mathrm{TF}$ is a transmembrane protein that serves as a high affinity receptor and cofactor for coagulation factors VII and VIIa $[37,38]$. Intracellular TF has been detected in approximately $1.5 \%$ of human $\mathrm{CD} 14^{+}$monocytes at homeostasis $[39,40]$. Exposure to pathogens results in rapid and transitory overexpression of TF [40, 41]. In conditions such as systemic sepsis, monocytes and macrophages respond with increased synthesis and release of TF; these findings have been linked to impaired coagulation responses [42]. As such, macrophage activation and the resulting increases in TF may work in tandem with ACE-2 downregulation and secondary accumulation of AT-II to promote dysregulated thrombosis. Platelets also express TF in in response to infectious states and can interact directly with monocytes and macrophages [43]; similar findings have been reported in response to ATII-mediated activation [44, 45].

Finally, it is critical to recognize the potential role played by antiphospholipid autoantibodies, including those that target cardiolipin and TNF- $\alpha$ induced $\beta 2$ glycoprotein-1 [46] among others [47]. As observed in patients with Antiphospholipid Antibody Syndrome (APS), these autoantibodies are associated with elevated levels TF [48, 49], and can thereby contribute to thrombotic disorders. Antiphospholipid antibodies have been detected in patients with COVID19; as such, similar clinical syndromes may result [11].

Figure 1 summarizes potential mechanisms that may promote thrombotic disorders in patients with severe COVID19. A role for $\mathrm{TF}$ as a central mediator is depicted. 


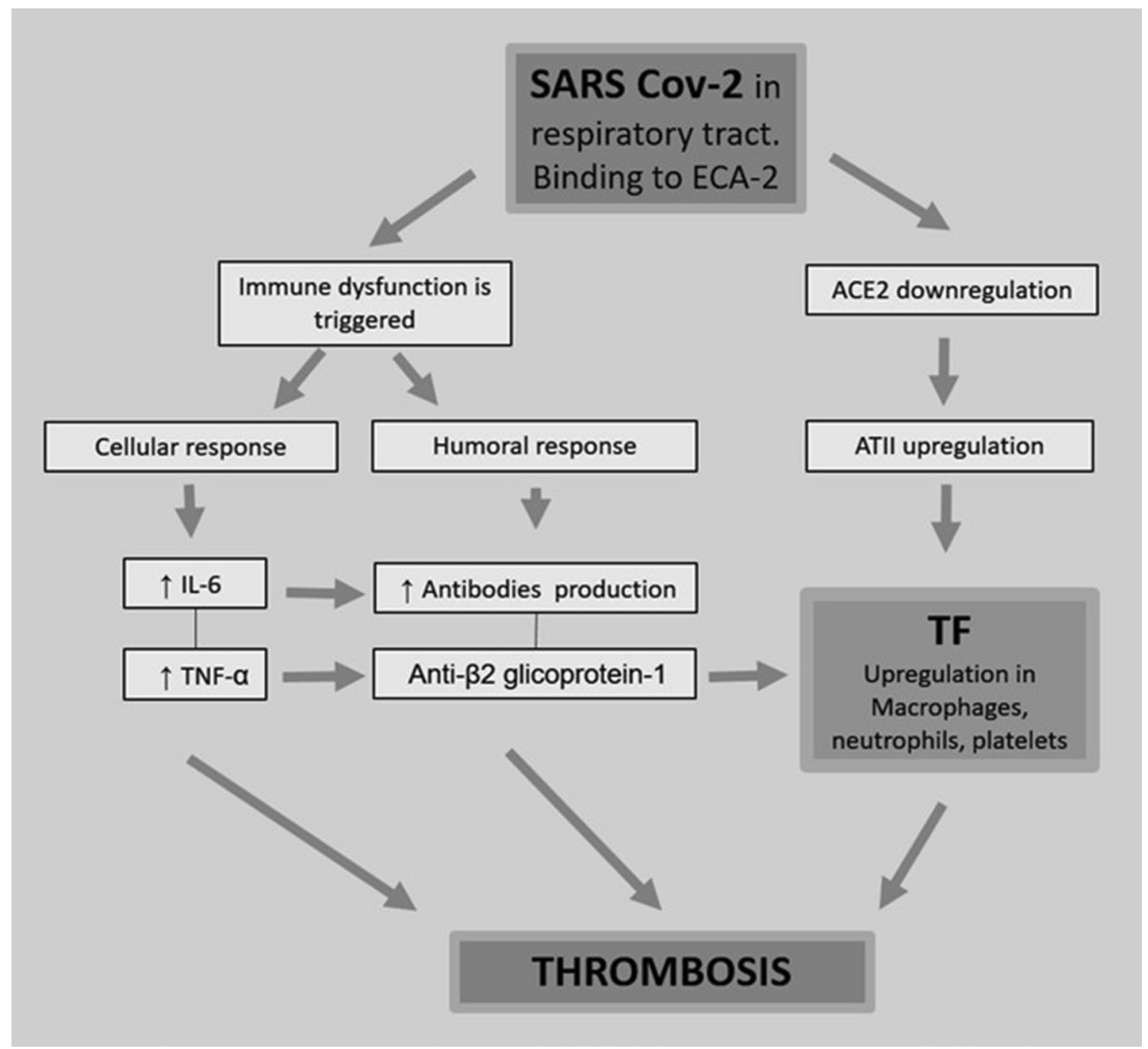

Fig. 1 Summary of the mechanisms potentially contributing to the prothrombotic state identified in patients with severe COVID-19. A role for $\mathrm{TF}$ is presented

\section{Anti-thrombotic therapy in COVID-19}

As noted above, coagulopathy is associated with a poor prognosis in severe SARS-CoV-2 infection; anticoagulant therapy may promote lower rates of mortality [50]. Likewise, immunomodulatory therapy with systemic glucocorticoids or via administration of antibodies against the IL-6 receptor (i.e., tocilizumab), might be useful toward the prevention of thrombotic states; administration of antithrombotic drugs may also reduce systemic inflammation.

Another possibility to consider is the use of agents that prevent platelet aggregation. The therapeutic role of aspirin (acetyl salicylic acid) as an inhibitor of platelet thromboxane remains unclear. Aspirin may also limit expression of TF by inhibiting its synthesis [51] and/or by facilitating production of a TF pathway inhibitor [52].

\section{Conclusion}

Entry of SARS-CoV-2 into cells that express the ACE-2 can promote a massive response that includes both local and systemic inflammatory syndromes. Among the potential mechanisms, virus-mediated downregulation of ACE-2 can promote a secondary increase in AT-II and thereby promote overexpression of TF. TF may be associated with other mechanisms that function in parallel and ultimately promote dysregulation of thrombosis. Further studies are required to explore this hypothesis and to determine whether a focus on TF might be helpful in elucidating the pathogenesis of thrombosis associated with COVID-19.

Acknowledgments The authors would like to thank Enago (www. enago.com) for the English language review. 


\section{Compliance with ethical standards}

Conflict of interest The authors declare that they have no conflict of interest.

\section{References}

1. Zhu N, Zhang D, Wang W et al (2020) A novel coronavirus from patients with pneumonia in China, 2019. N Engl J Med 382:727-733

2. Zhou F, Yu T, Du R, Fan G, Liu Y et al (2020) Clinical course and risk factors for mortality of adult inpatients with COVID19 in Wuhan, China: a retrospective cohort study. Lancet 395:1054-1062

3. https://www.who.int/emergencies/diseases/novel-coronaviru s-2019

4. Yan R, Zhang Y, Li Y et al (2020) Structural basis for the recognition of SARS-CoV-2 by full-length human ACE2. Science 367:1444-1448

5. Wang D, Hu B, Hu C et al (2020) Clinical characteristics of 138 hospitalized patients with 2019 novel coronavirus-infected pneumonia in Wuhan, China. JAMA 323:1061-1069. https://doi. org/10.1001/jama.2020.1585

6. Khosravani H, Rajendram P, Notario L et al (2020) Protected code stroke: hyperacute stroke management during the coronavirus disease 2019 (COVID-19) pandemic. Stroke. https://doi.org/10.1161/ STROKEAHA.120.029838

7. Zhang Y, Cao W, Xiao M et al (2020) Clinical and coagulation characteristics of 7 patients with critical COVID-2019 pneumonia and acro-ischemia. Zhonghua Xue Ye Xue Za Zhi 41:E006

8. Lillicrap D (2020) Disseminated intravascular coagulation in patients with 2019-nCoV pneumonia. J Thromb Haemost 18:786-787

9. Danzi GB, Loffi M, Galeazzi G, Gherbesi E (2020) Acute pulmonary embolism and COVID-19 pneumonia: a random association? Eur Heart J 41:1858

10. Tang N, Li D, Wang X, Sun Z (2020) Abnormal coagulation parameters are associated with poor prognosis in patients with novel coronavirus pneumonia. J Thromb Haemost 18:844-847

11. Zhang Y, Xiao M, Zhang S et al (2020) Coagulopathy and antiphospholipid antibodies in patients with Covid-19. N Engl J Med. https://doi.org/10.1056/NEJMc2007575

12. Hamming I, Cooper ME, Haagmans BL et al (2007) The emerging role of ACE2 in physiology and disease. J Pathol 212:1-11

13. Li W, Moore MJ, Vasilieva N et al (2003) Angiotensin-converting enzyme 2 is a functional receptor for the SARS coronavirus. Nature 426:450-454

14. Alvarez A, Cerdá-Nicolás M, Nabah YNA et al (2004) Direct evidence of leukocyte adhesion in arterioles by angiotensin II. Blood 104:402-408

15. Xudong X, Junzhu C, Xingxiang W et al (2006) Age- and gender-related difference of ACE2 expression in rat lung. Life Sci 78:2166-2171

16. Yoon H, Kim E, Kim M et al (2016) Age-associated changes in the vascular renin-angiotensin system in mice. Oxid Med Cell Longev 2016:1-14

17. Hung YH, Hsieh WY, Hsieh JS et al (2016) Alternative roles of STAT3 and MAPK signaling pathways in the MMPs activation and progression of lung injury induced by cigarette smoke exposure in ACE2 knockout mice. Int J Biol Sci 12:454-465

18. Grobe JL, Sarkissian SD, Stewart JM et al (2007) ACE2 overexpression inhibits hypoxia-induced collagen production by cardiac fibroblasts. Science (London) 113:357-364
19. Crackower MA, Sarao R, Oudit GY et al (2002) Angiotensinconverting enzyme 2 is an essential regulator of heart function. Nature 417:822-828

20. Batlle D, Soler MJ, Ye M (2010) ACE2 and diabetes: ACE of ACEs? Diabetes 59:2540-2548

21. Leung JM, Yang CX, Tam A et al (2020) ACE-2 expression in the small airway epithelia of smokers and COPD patients: implications for COVID-19. Eur Respir J 55:2000688. https:// doi.org/10.1183/13993003.00688-2020

22. Ding Y, Wang H, Shen $\mathrm{H}$ et al (2003) The clinical pathology of severe acute respiratory syndrome (SARS): a report from China. J Pathol 200:282-289

23. Malha L, Mueller F, Pecker M et al (2020) COVID-19 and the renin-angiotensin system. Kidney Int Rep. https://doi. org/10.1016/j.ekir.2020.03.024

24. Harrison DG, Guzik TJ, Lob HE et al (2011) Inflammation, immunity, and hypertension. Hypertension 57:132-140

25. Senchenkova EY, Russell J, Kurmaeva E et al (2011) Role of T lymphocytes in angiotensin II-mediated microvascular thrombosis. Hypertension (Dallas, Tex 1979) 58:959-965

26. Shen XZ, Okwan-Duodu D, Blackwell W-L et al (2014) Myeloid expression of angiotensin-converting enzyme facilitates myeloid maturation and inhibits the development of myeloidderived suppressor cells. Lab Invest 94:536-544

27. Wong CK, Lam CWK, Wu AKL et al (2004) Plasma inflammatory cytokines and chemokines in severe acute respiratory syndrome. Clin Exp Immunol 136:95-103

28. Mehta P, McAuley DF, Brown M, Sanchez E, Tattersall RS, Manson JJ (2020) COVID-19: consider cytokine storm syndromes and immunosuppression. Lancet (London, England) 395:1033-1034

29. Pedersen SF, Ho Y-C (2020) SARS-CoV-2: a storm is raging. J Clin Invest. https://doi.org/10.1172/JCI137647

30. Dmitrieva NI, Burg MB (2015) Elevated sodium and dehydration stimulate inflammatory signaling in endothelial cells and promote atherosclerosis. PLoS ONE 10:e0128870

31. Brown NJ, Vaughan DE (2000) Prothrombotic effects of angiotensin. Adv Intern Med 45:419-429

32. Hou T, Tieu B, Ray S et al (2008) Roles of IL-6-gp130 signaling in vascular inflammation. Curr Cardiol Rev 4:179-192

33. Ishibashi T, Kimura H, Shikama $Y$ et al (1989) Interleukin-6 is a potent thrombopoietic factor in vivo in mice. Blood 74:1241-1244

34. Guzik TJ, Hoch NE, Brown KA et al (2007) Role of the T cell in the genesis of angiotensin II induced hypertension and vascular dysfunction. J Exp Med 204:2449-2460

35. Sun J, Axelsson J, Machowska A et al (2016) Biomarkers of cardiovascular disease and mortality risk in patients with advanced CKD. Clin J Am Soc Nephrol 11:1163-1172

36. Bautista LE, Vera LM, Arenas IA, Gamarra G (2005) Independent association between inflammatory markers (C-reactive protein, interleukin-6, and TNF- $\alpha$ ) and essential hypertension. J Hum Hypertens 19:149-154

37. Nemerson Y (1988) Tissue factor and hemostasis. Blood 71:1-8

38. Mackman N, Tilley RE, Key NS (2007) Role of the extrinsic pathway of blood coagulation in hemostasis and thrombosis. Arterioscler Thromb Vasc Biol 27:1687-1693

39. Egorina EM, Sovershaev MA, Bjørkøy G et al (2005) Intracellular and surface distribution of monocyte tissue factor: application to intersubjective variability. Arterioscler Thromb Vasc Biol 25:1493-1498

40. Gregory SA, Morrissey JH, Edgington TS (1989) Regulation of tissue factor gene expression in the monocyte procoagulant response to endotoxin. Mol Cell Biol 9:2752-2755

41. Drake TA, Cheng J, Chang A, Taylor FBJ (1993) Expression of tissue factor, thrombomodulin, and E-selectin in baboons with lethal Escherichia coli sepsis. Am J Pathol 142:1458-1470 
42. Chen X, Lao Y, Yi J, Yang J et al (2020) SENP3 in monocytes/ macrophages up-regulates tissue factor and mediates lipopolysaccharide-induced acute lung injury by enhancing JNK phosphorylation. J Cell Mol Med. https://doi.org/10.1111/jcmm.15199

43. Lösche W (2005) Platelets and tissue factor. Platelets 16:313-319

44. Brambilla M, Gelosa P, Rossetti L et al (2018) Impact of angiotensin-converting enzyme inhibition on platelet tissue factor expression in stroke-prone rats. J Hypertens 36:1360-1371

45. Ozolina A, Sarkele M, Sabelnikovs O et al (2016) Activation of coagulation and fibrinolysis in acute respiratory distress syndrome: a prospective pilot study. Front Med 3:64

46. Hollerbach A, Müller-Calleja N, Canisius A et al (2020) Induction of tissue factor expression by anti- $\beta 2$-glycoprotein I is mediated by tumor necrosis factor $\alpha$. J Thromb Thrombolysis 49:228-234

47. Miyakis S, Lockshin MD, Atsumi T et al (2006) International consensus statement on an update of the classification criteria for definite antiphospholipid syndrome (APS). J Thromb Haemost 4:295-306

48. Dobado-Berrios PM, López-Pedrera C, Velasco F et al (1999) Increased levels of tissue factor mRNA in mononuclear blood cells of patients with primary antiphospholipid syndrome. Thromb Haemost 82:1578-1582
49. Joan-Carles R, Dolors T, Josep F et al (1996) Hypercoagulable state in patients with antiphospholipid syndrome is related to high induced tissue factor expression on monocytes and to low free protein S. Arterioscler Thromb Vasc Biol 16:1319-1326

50. Tang N, Bai H, Chen X et al (2020) Anticoagulant treatment is associated with decreased mortality in severe coronavirus disease 2019 patients with coagulopathy. J Thromb Haemost. https://doi. org/10.1111/jth.14817

51. Osnes LT, Foss KB, Joø GB et al (1996) Acetylsalicylic acid and sodium salicylate inhibit LPS-induced NF-kappa B/c-Rel nuclear translocation, and synthesis of tissue factor (TF) and tumor necrosis factor alfa (TNF- $\alpha$ ) in human monocytes. Thromb Haemost 76:970-976

52. Undas A, Brummel-Ziedins KE, Mann KG (2007) Antithrombotic properties of aspirin and resistance to aspirin: beyond strictly antiplatelet actions. Blood 109:2285-2292

Publisher's Note Springer Nature remains neutral with regard to jurisdictional claims in published maps and institutional affiliations. 